\title{
Reduced Kidney Function Estimated by Cystatin C and Clinical Outcomes in Hypertensive Patients with Coronary Artery Disease: Association with Homocysteine and Other Cardiovascular Risk Factors
}

\author{
Zofia Dzielinska $^{a} \quad$ Andrzej Januszewicz ${ }^{b} \quad$ Andrzej Wiecek $^{f} \quad$ Aleksander Prejbisz $^{b}$ \\ Tomasz Zielinskic Jerzy Chudek $^{f}$ Magdalena Makowiecka-Cieslab \\ Marcin Demkow ${ }^{\mathrm{a}}$ Pawel Tyczynski ${ }^{\mathrm{a}} \quad$ Magdalena Januszewicz ${ }^{\mathrm{d}}$ Witold Ruzyllo $^{\mathrm{a}}$ \\ Marek Naruszewicz ${ }^{\mathrm{e}}$

\begin{abstract}
${ }^{\mathrm{a}}$ 1st Department of Coronary Artery Disease, ${ }^{\mathrm{b}}$ Department of Hypertension, and ${ }^{\mathrm{c}}$ Department of Heart Failure and Transplantation, Institute of Cardiology, ${ }^{\mathrm{d}}$ 2nd Department of Clinical Radiology, and ${ }^{\mathrm{e}}$ Department of Pharmacognosy and Molecular Basis of Phythotherapy, Medical University of Warsaw, Warsaw, and ${ }^{\mathrm{f} D e p a r t m e n t}$ of Nephrology, Endocrinology and Metabolic Diseases, Medical University of Silesia, Katowice, Poland
\end{abstract}

\section{Key Words}

Coronary artery disease $\cdot$ Hypertension $\cdot$ Cystatin C . Homocysteine $\cdot$ Kidney function $\cdot$ Cardiovascular risk factors · Cardiovascular events

\begin{abstract}
Aims: To evaluate the association between serum cystatin $C$ and homocysteine concentrations, cardiovascular risk factors and cardiovascular events in hypertensive patients with coronary artery disease (CAD). Methods: 260 patients with hypertension and CAD (mean age $56.9 \pm 9.3$ ) were included. During a mean 40-month follow-up the combined endpoint of death from all causes, non-fatal myocardial infarction and stroke or coronary revascularization was assessed. $\boldsymbol{R e}$ sults: Subjects in the highest serum cystatin $C$ quartile (>103.4 $\mathrm{nmol} / \mathrm{l})$ as compared with the lowest were older, were characterized by a higher frequency of multivessel CAD, higher levels of homocysteine (13.2 \pm 5.2 vs. $11.4 \pm 4.2$ $\mu \mathrm{mol} / \mathrm{l} ; \mathrm{p}<0.01)$, fibrinogen and high-sensitivity C-reactive protein and by an increased intima-media thickness. Com-
\end{abstract}

bined end-point occurred twice as frequently in the 4th quartile of serum cystatin $C$ as compared with the 1st quartile (10.8 vs. $20.3 \% ; p=0.11$ ). In an univariate analysis, but not in a multivariate model, cystatin $C$ concentration predicted the combined end-point $(\operatorname{Exp}(B)=1.096 ; p<0.05)$. Conclusion: In hypertensive patients with $C A D$, serum cystatin $C$ level was independently associated with the extent of CAD, homocysteine plasma level and traditional vascular risk factors. However, serum cystatin C concentration did not independently predict the combined end-point.

Copyright $\odot 2010$ S. Karger AG, Basel

\section{Introduction}

Cystatin $\mathrm{C}$ has been shown to be a better endogenous marker of glomerular filtration rate (GFR) than creatinine which does not appear to be affected by age, gender or muscle mass and is more sensitive to mild decrements in GFR than serum creatinine $[1,2]$. Recent reports have indicated that in the elderly community-based cohorts,

\section{KARGER}

Fax +41613061234 E-Mail karger@karger.ch www.karger.com

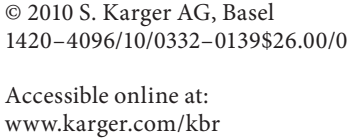

Prof. Andrzej Januszewicz

Department of Hypertension, Institute of Cardiology

Alpejska 42, PL-04-628 Warsaw (Poland)

Tel. +48 223434 333, Fax +48 223434517

E-Mail ajanu@op.pl 
Table 1. Baseline clinical characteristics of patients according to cystatin $\mathrm{C}$ concentration quartile

\begin{tabular}{|c|c|c|c|c|c|c|c|}
\hline & \multirow[t]{2}{*}{ All patients } & \multicolumn{4}{|c|}{ Cystatin $\mathrm{C}$ concentration, $\mathrm{nmol} / \mathrm{l}$} & \multicolumn{2}{|c|}{ Significance } \\
\hline & & $\mathrm{I},<72.5$ & II, 72.5-83.4 & III, 83.5-103.4 & $\mathrm{IV}, \geq 103.5$ & $\begin{array}{l}\text { all } \\
\text { groups }\end{array}$ & IV vs. I \\
\hline Number & 260 & 65 & 64 & 67 & 64 & - & - \\
\hline Age, years & $56.9 \pm 9.3$ & $55.1 \pm 10.1$ & $55.9 \pm 8.4$ & $56.0 \pm 10.8$ & $59.0 \pm 8.9$ & 0.12 & $<0.05$ \\
\hline Female gender, $\%$ & 30.8 & 32.3 & 28.1 & 28.4 & 34.4 & - & - \\
\hline BMI & $28.8 \pm 3.8$ & $28.5 \pm 3.2$ & $29.0 \pm 3.7$ & $28.8 \pm 3.8$ & $28.9 \pm 4.4$ & - & - \\
\hline BP office, $\mathrm{mm} \mathrm{Hg}$ & $136 \pm 22 / 84 \pm 14$ & $138 \pm 22 / 86 \pm 14$ & $133 \pm 19 / 84 \pm 13$ & $137 \pm 23 / 83 \pm 13$ & $136 \pm 24 / 83 \pm 16$ & - & - \\
\hline BP 24-hour, mm Hg & $118 \pm 13 / 72 \pm 8$ & $116 \pm 12 / 71 \pm 7$ & $118 \pm 13 / 73 \pm 8$ & $119 \pm 13 / 71 \pm 9$ & $118 \pm 15 / 71 \pm 9$ & - & - \\
\hline HR, beats/min & $69 \pm 7$ & $70 \pm 8$ & $69 \pm 7$ & $68 \pm 8$ & $69 \pm 7$ & - & - \\
\hline PP office, $\mathrm{mm} \mathrm{Hg}$ & $49 \pm 12$ & $45 \pm 14$ & $47 \pm 14$ & $50 \pm 13$ & $49 \pm 12$ & - & 0.07 \\
\hline PP 24-hour, mm Hg & $47 \pm 10$ & $45 \pm 12$ & $45 \pm 10$ & $48 \pm 9$ & $47 \pm 10$ & - & - \\
\hline History of MI, \% & 43.8 & 38.5 & 51.6 & 43.3 & 42.2 & - & - \\
\hline Diabetes mellitus, \% & 15.8 & 17.2 & 15.6 & 16.4 & 14.1 & - & - \\
\hline Hyperlipidemia, \% & 73.2 & 75.0 & 75.8 & 78.5 & 63.5 & - & - \\
\hline Multivessel CAD, \% & 49.2 & 41.5 & 46.9 & 46.3 & 62.5 & 0.093 & $<0.05$ \\
\hline Carotid arteries atherosclerosis, $\%$ & 75.9 & 79.7 & 80.4 & 67.2 & 76.3 & - & - \\
\hline Renal arteries atherosclerosis, $\%$ & 15.8 & 18.5 & 14.1 & 11.9 & 18.8 & - & - \\
\hline Femoral arteries atherosclerosis, \% & 75.1 & 71.7 & 80.4 & 67.9 & 80.4 & - & - \\
\hline Former or current smokers, \% & 22.8 & 25.0 & 20.3 & 23.9 & 21.9 & - & - \\
\hline EF echocardiography, \% & $62 \pm 10$ & $63 \pm 10$ & $63 \pm 10$ & $61 \pm 11$ & $61 \pm 10$ & - & - \\
\hline $\mathrm{IMT}, \mathrm{mm}$ & $1.16 \pm 0.37$ & $1.12 \pm 0.35$ & $1.08 \pm 0.28$ & $1.18 \pm 0.42$ & $1.25 \pm 0.38$ & 0.07 & $<0.05$ \\
\hline LVMI, $\mathrm{g} / \mathrm{m}^{2}$ & $120.5 \pm 30.6$ & $117.5 \pm 25.6$ & $127.0 \pm 39.7$ & $115.3 \pm 25.9$ & $122.4 \pm 28.5$ & - & - \\
\hline Nitrates, \% & 62.7 & 58.5 & 59.4 & 64.2 & 68.8 & - & - \\
\hline Diuretics, \% & 17.3 & 18.5 & 15.6 & 11.9 & 23.4 & - & - \\
\hline$\beta$-Blockers, $\%$ & 83.1 & 86.2 & 73.4 & 77.6 & 95.3 & $<0.01$ & 0.07 \\
\hline ACEI or ARB, \% & 28.1 & 29.2 & 26.6 & 29.9 & 26.6 & - & - \\
\hline $\mathrm{CCB}, \%$ & 46.5 & 44.6 & 37.5 & 47.8 & 56.3 & - & - \\
\hline Statins, \% & 53.8 & 49.2 & 56.3 & 62.7 & 46.9 & - & - \\
\hline Number of antihypertensive drugs ${ }^{\mathrm{a}}$ & & 2 & 2 & 2 & 2 & - & - \\
\hline $\mathrm{CCS}_{\text {class }} \mathrm{a}^{\mathrm{a}}$ & 2 & 2 & 2 & 2 & 2 & - & - \\
\hline
\end{tabular}

$\mathrm{BMI}=$ Body mass index $\mathrm{BP}=$ blood pressure; $\mathrm{HR}=$ heart rate; $\mathrm{PP}=$ pulse pressure; $\mathrm{MI}=$ myocardial infarction; $\mathrm{EF}=$ ejection fraction; $\mathrm{IMT}=\mathrm{intima}$ media thickness; $\mathrm{LVMI}=$ left ventricle mass index; $\mathrm{ACEI}=$ angiotensin-converting enzyme inhibitor; $\mathrm{ARB}=$ angiotensin II receptor blocker; $\mathrm{CCB}=$ calcium channel blocker; CCS = Canadian Cardiovascular Society.

${ }^{\text {a }}$ Data are shown as median.

serum cystatin $\mathrm{C}$ concentration seems to be a better predictor of all-cause mortality, cardiovascular events and incidence of heart failure (HF) than either serum creatinine or creatinine-based estimating equations $[3,4]$. It has also been reported that a higher serum cystatin $\mathrm{C}$ concentration was associated with all-cause mortality, cardiovascular events and incidence of HF among subjects with coronary artery disease (CAD) [1-11]. Data from the NHANES III showed that in a large sample of US adults without traditional markers of kidney disease, elevated serum cystatin $C$ level was associated with a progressively increased cardiovascular disease [10].

The aim of the present study was to evaluate the association between serum cystatin $\mathrm{C}$ concentration, cardiovascular risk factors and target organ damage in hypertensive patients with multivessel CAD and normal to moderate chronic kidney disease. We have also examined the association between serum cystatin $C$ concentration and cardiovascular events during the follow-up period.

\section{Material and Methods}

From the group of 333 previously described consecutive patients with CAD and hypertension, who underwent both coronary and renal angiography, 260 patients (mean age $56.9 \pm 9.3$ years, $197 \mathrm{M}, 77 \mathrm{~F}$ ) participated in the follow-up observation (32 patients with renal artery stenosis, 27 patients who refused to participate in the follow-up and 14 patients for whom serum cystatin $\mathrm{C}$ evaluation was not possible were excluded) [5]. Baseline demographics and clinical data are presented in table $1.114(43.8 \%)$ patients had a history of previous myocardial infarction (MI), 41 (15.8\%) diabetes mellitus, 190 (73.7\%) hyperlipidemia, and 59 $(22.7 \%)$ a history of smoking. 
In all patients enrolled in this study, clinically indicated nonemergency coronary angiography followed by renal angiography was performed during hospitalization. All patients were treated with antihypertensive medications. A significant stenosis of the coronary artery was diagnosed when the degree of stenosis was $\geq 50 \%$ of diameter. According to the number of stenosed coronary arteries, patients were divided into two groups: with multivessel diseases (two or more) or without multivessel diseases (one or with no significant stenosis). Carotid arteries atherosclerosis, renal arteries atherosclerosis or femoral arteries atherosclerosis were diagnosed by a duplex Doppler ultrasound or angiography, respectively. Patients with significant renal artery stenosis $(\geq 50 \%$ of diameter) were not included into this study.

The clinical data included clinical and biochemical characteristics, office blood pressure (BP) and 24-hour BP monitoring as described previously [5]. Baseline serum creatinine was measured before the cardiovascular procedure. Renal function was estimated using the eGFR based upon the Cockroft-Gault formula or Modification of Diet in Renal Disease formula. According to the eGFR, patients were classified into a group with a normal (eGFR $\left.\geq 90 \mathrm{ml} / \mathrm{min} / 1.73 \mathrm{~m}^{2}\right)$, mild $\left(90>\mathrm{eGFR} \geq 60 \mathrm{ml} / \mathrm{min} / 1.73 \mathrm{~m}^{2}\right)$ or moderate $\left(60>\right.$ eGFR $\left.\geq 30 \mathrm{ml} / \mathrm{min} / 1.73 \mathrm{~m}^{2}\right)$ renal impairment.

Serum cystatin $C$ concentrations were measured on previously frozen samples (stored at $-80^{\circ} \mathrm{C}$ ) by enzyme-linked immunosorbent assay (DRG Instruments $\mathrm{GmbH}$, Marburg, Germany) and were reported as nmol/l. Intra- and interassay coefficients of variation were $5.0-9.6$ and $4.8-6.2 \%$ for high $(217.2 \mathrm{nmol} / \mathrm{l})$ and low $(44.9 \mathrm{nmol} / \mathrm{l})$ concentrations, respectively.

Twenty-four-hour BP measurements were performed with a SpaceLabs 90207 or 90217 recorders (SpaceLabs, Redmond, Wash., USA) while patients were staying at hospital in a stable clinical state. BP readings were obtained at $15-\mathrm{min}$ intervals from 06:00 to 22:00 $\mathrm{h}$ and at 30-min intervals from 22:00 to $06: 00 \mathrm{~h}$. Mean systolic and diastolic BP (SBP and DBP) were calculated for the daytime, the nighttime and the 24-hour periods without applying any criteria.

The carotid ultrasound followed by a duplex color Doppler examination was performed in the supine position, with a Philips ATL 5000 and a linear probe 7.5-12 MHz. Both left and right common carotid arteries were analyzed. Multiple measurements on the distal wall from anterior, lateral and posterior longitudinal views were recorded. Maximal intima-media thickness (IMT) was measured in two segments $1 \mathrm{~cm}$ from the flow divider caudally (carotid bulb) and $1 \mathrm{~cm}$ caudally from the beginning of the common carotid bulb (common carotid). The IMT value was calculated as an arithmetical mean from bulb and common carotid segments of both sides.

Diabetes mellitus was defined as a serum glucose level of 7.0 $\mathrm{mmol} / \mathrm{l}$ or more fasting or $11.1 \mathrm{mmol} / \mathrm{l}$ or more $2 \mathrm{~h}$ following standard oral glucose challenge or medication use for diabetes mellitus. Hyperlipidemia was defined as the presence of active pharmacological antilipemic treatment or plasma levels exceeding 5.2 $\mathrm{mmol} / \mathrm{l}$ of total cholesterol or $>3.4 \mathrm{mmol} / \mathrm{l}$ of low- or high-density lipoprotein cholesterol level $<0.9 \mathrm{mmol} / \mathrm{l}$ or triglycerides plasma level $>1.5 \mathrm{mmol} / \mathrm{l}$

In all 260 patients, follow-up was conducted at mean 40 months after the discharge from the hospital. Information which included current health status, anginal symptoms, exercise tolerance, medications and occurrence of cardiovascular events during follow-up was obtained from each patient by use of a mailed standardized questionnaire. Information regarding secondary cardiovascular events and treatment since discharge from the inhospital was obtained from the primary care physicians. Out-ofhospital information about death was obtained from the National Registry on Mortality. The combined end-points of death from all causes, non-fatal acute MI, revascularization (coronary artery bypass grafting $[\mathrm{CABG}]$ or percutaneous coronary intervention [PCI]) and non-fatal stroke were assessed.

A statistical analysis was performed with SPSS version 15.0 software (SPSS Polska Sp. z o.o., Cracow, Poland). The differences between continuous variables between groups were assessed by Student's t test with Levene's test for equality of variances. In case of non-equality of variances and for discrete variables, the MannWhitney U test was employed. For categorical variables, comparisons were performed using the $\chi^{2}$ test with Yates' correction for continuity. One-way ANOVA test was employed for comparison of differences between serum cystatin C quartiles. For comparison of variables, a univariate Cox analysis was performed to determine the influence of variables analyzed on the defined endpoint. Variables which were significant in the univariate Cox analysis were included in the multivariate Cox model. The area under the receiver operating characteristic (ROC) curve was calculated. Differences were considered statistically significant when $\mathrm{p}<0.05$.

\section{Results}

260 patients (mean age $56.9 \pm 9.3$ years) were included into analysis. During the follow-up, 10 deaths from all causes (3.8\%), $6 \mathrm{MI}$ (2.3\%), 4 strokes (1.5\%), 20 PCI (7.7\%) and 3 CABG (1.2\%) occurred. According to eGFR, 6 (2.3\%) patients had normal renal function, 168 (64.6\%) mild and 86 (33.1\%) moderate renal impairment.

At baseline the median serum concentration of cystatin $\mathrm{C}$ was $83.9 \mathrm{nmol} / \mathrm{l}$ (interquartile range 72.5-103.4 $\mathrm{nmol} / \mathrm{l})$. Baseline characteristics of the study sample and biochemical variables by serum cystatin C quartile groups are shown in tables 1 and 2 . When compared with those in the lowest serum cystatin $C$ quartile $(<72.5 \mathrm{nmol} / \mathrm{l})$, subjects in the highest serum cystatin $C$ quartile $(>103.4$ nmol/l) were older and characterized by a higher frequency of multivessel CAD and higher plasma levels of serum homocysteine, fibrinogen and high-sensitivity $\mathrm{C}$ reactive protein (hsCRP) (tables 1,2 ). Additionally, patients in the highest serum cystatin $C$ quartile were characterized by a more pronounced increase in IMT.

The values of 24-hour BP monitoring and office BP were similar among groups except pulse pressure (PP) which tended to be higher in the highest serum cystatin C quartile as compared with the lowest. Increasing serum cystatin $\mathrm{C}$ levels were associated with higher homocysteine, hsCRP, and fibrinogen concentrations (table 2). As expected, plasma creatinine concentration was higher 
Table 2. Baseline biochemical variables of patients according to cystatin C concentration quartile

\begin{tabular}{|c|c|c|c|c|c|c|c|}
\hline & \multirow[t]{2}{*}{ All patients } & \multicolumn{4}{|c|}{ Cystatin C concentration, nmol/l } & \multicolumn{2}{|c|}{ Significance } \\
\hline & & $\mathrm{I},<72.5$ & II, $72.5-83.4$ & III, 83.5-103.4 & $\mathrm{IV}, \geq 103.5$ & all groups & IV vs. I \\
\hline Number & 260 & 65 & 64 & 67 & 64 & - & - \\
\hline Creatinine, $\mu \mathrm{mol} / \mathrm{l}$ & $109 \pm 27$ & $105 \pm 17$ & $106 \pm 18$ & $107 \pm 29$ & $118 \pm 36$ & $<0.05$ & $<0.05$ \\
\hline Creatinine clearance, $\mathrm{ml} / \mathrm{min}$ & $80.7 \pm 23.9$ & $83.6 \pm 22.0$ & $83.5 \pm 21.3$ & $82.25 \pm 26.3$ & $73.1 \pm 24.5$ & $<0.05$ & $<0.01$ \\
\hline $\mathrm{GFR}, \mathrm{ml} / \mathrm{min} / 1.73 \mathrm{~m}^{2}$ & $64.3 \pm 13.4$ & $65.6 \pm 11.6$ & $66.3 \pm 12.6$ & $66.9 \pm 13.9$ & $58.4 \pm 13.8$ & $<0.01$ & $<0.01$ \\
\hline Uric acid, $\mathrm{mmol} / \mathrm{l}$ & $5.0 \pm 1.4$ & $5.1 \pm 1.1$ & $5.3 \pm 1.6$ & $4.6 \pm 1.3$ & $5.2 \pm 1.4$ & 0.062 & - \\
\hline Leukocytes, $10^{3} / \mu \mathrm{l}$ & $7.0 \pm 1.9$ & $7.1 \pm 2.2$ & $7.0 \pm 1.8$ & $6.9 \pm 1.5$ & $7.0 \pm 2.1$ & - & - \\
\hline Hemoglobin, g/dl & $14.5 \pm 2.9$ & $14.8 \pm 0.5$ & $14.3 \pm 1.1$ & $14.1 \pm 1.5$ & $14.6 \pm 4.4$ & - & - \\
\hline Platelets, $10^{3} / \mu \mathrm{l}$ & $216 \pm 61$ & $214 \pm 53$ & $222 \pm 78$ & $222 \pm 61$ & $207 \pm 49$ & - & - \\
\hline Fibrinogen, $\mu \mathrm{mol} / \mathrm{l}$ & $10.2 \pm 2.8$ & $9.4 \pm 1.9$ & $10.2 \pm 2.5$ & $10.1 \pm 3.1$ & $11.1 \pm 3.3$ & $<0.05$ & $<0.01$ \\
\hline Serum Na, mmol/l & $141 \pm 3$ & $142 \pm 3$ & $140 \pm 4$ & $141 \pm 3$ & $142 \pm 3$ & - & - \\
\hline Serum K, mmol/l & $4.5 \pm 0.4$ & $4.4 \pm 0.4$ & $4.4 \pm 0.4$ & $4.5 \pm 0.4$ & $4.5 \pm 0.4$ & - & - \\
\hline hsCRP, mg/l & $5.5 \pm 3.8$ & $4.1 \pm 2.8$ & $5.6 \pm 4.2$ & $5.5 \pm 3.9$ & $6.9 \pm 3.9$ & $<0.01$ & $<0.001$ \\
\hline Serum cholesterol, mmol/l & $4.9 \pm 1.0$ & $5.0 \pm 1.0$ & $4.9 \pm 1.0$ & $4.8 \pm 1.0$ & $5.1 \pm 1.1$ & - & - \\
\hline Serum triglyceride, $\mathrm{mmol} / \mathrm{l}$ & $1.8 \pm 1.0$ & $1.9 \pm 0.9$ & $1.8 \pm 1.0$ & $1.8 \pm 0.9$ & $1.8 \pm 1.1$ & - & - \\
\hline $\mathrm{HDL}, \mathrm{mmol} / \mathrm{l}$ & $1.2 \pm 0.3$ & $1.2 \pm 0.3$ & $1.2 \pm 0.3$ & $1.2 \pm 0.2$ & $1.2 \pm 0.3$ & - & - \\
\hline $\mathrm{LDL}, \mathrm{mmol} / \mathrm{l}$ & $3.0 \pm 0.9$ & $3.0 \pm 0.9$ & $2.9 \pm 0.8$ & $2.8 \pm 0.8$ & $3.1 \pm 1.0$ & - & - \\
\hline Fasting blood glucose, $\mathrm{mmol} / \mathrm{l}$ & $5.8 \pm 15$ & $5.9 \pm 1.6$ & $5.9 \pm 1.6$ & $5.9 \pm 1.7$ & $5.5 \pm 1.0$ & - & - \\
\hline Homocysteine, $\mu \mathrm{mol} / \mathrm{l}$ & $11.4 \pm 4.2$ & $10.5 \pm 2.9$ & $10.9 \pm 4.2$ & $10.9 \pm 3.9$ & $13.2 \pm 5.2$ & $<0.01$ & $<0.01$ \\
\hline
\end{tabular}

GFR = Glomerular filtration rate; hsCRP = high-sensitivity C-reactive protein; HDL = high-density lipoprotein; LDL = low-density lipoprotein.

Table 3. Baseline correlations between cystatin C concentration and selected parameters

\begin{tabular}{lll}
\hline & $\begin{array}{c}\text { Unadjusted } \\
\text { coefficient } \beta\end{array}$ & Multivariate \\
\hline Age, years & $0.15^{*}$ & - \\
Multivessel disease, $\%$ & $0.17^{* *}$ & $0.15^{*}$ \\
Creatinine, $\mu \mathrm{mol} / \mathrm{l}$ & $0.23^{* * *}$ & - \\
Creatinine clearance, $\mathrm{ml} / \mathrm{min}$ & $-0.18^{* *}$ & - \\
GFR, $\mathrm{ml} / \mathrm{min} / 1.73 \mathrm{~m}^{2}$ & $-0.22^{* * *}$ & - \\
Fibrinogen, $\mu \mathrm{mol} / \mathrm{l}$ & $0.235^{* * *}$ & $0.16^{*}$ \\
hsCRP, g/l & $0.255^{* * *}$ & $0.15^{*}$ \\
Homocysteine, $\mu \mathrm{mol} / \mathrm{l}$ & $0.30^{* * *}$ & $0.24^{* *}$ \\
IMT, mm & $0.185^{* *}$ & - \\
\hline
\end{tabular}

GFR = Glomerular filtration rate; hsCRP = high-sensitivity C-reactive protein; IMT = intima media thickness.

${ }^{*} \mathrm{p}<0.05 ;{ }^{* *} \mathrm{p}<0.01 ;{ }^{* *} \mathrm{p}<0.001$.

and eGFR was lower among subjects with a higher serum cystatin $\mathrm{C}$ level. There were no significant differences in treatment modality or in median number of antihypertensive drugs between patients with different serum cystatin $\mathrm{C}$ levels, except for the $\beta$-blockers which tended to be used more frequently by patients with a higher serum cystatin C level.

In the whole study group, there were significant correlations between serum cystatin $\mathrm{C}$ level and serum homocysteine, hsCRP, fibrinogen, creatinine, eGFR, IMT, creatinine clearance, multivessel CAD, as well as with age (table 3). In a multivariate analysis adjusted for age, creatinine concentration and eGFR only correlations with multivessel CAD, serum homocysteine, fibrinogen and hsCRP levels were still significant (table 3).

Baseline clinical characteristics of patients according to the occurrence of end-point are presented in table 4 . Patients with combined end-point were characterized by higher mean 24-hour SBP levels (124 vs. $116 \mathrm{~mm} \mathrm{Hg;} \mathrm{p}$ 0.001), 24-hour PP (51 vs. $45 \mathrm{~mm} \mathrm{Hg;}<<0.01$ ), heart rate (HR) (71 vs. 68 beats/min; $\mathrm{p}<0.05$ ) and by a higher serum cystatin C concentration ( 93.6 vs. $86.1 \mathrm{nmol} / \mathrm{l} ; \mathrm{p}<0.05$ ) at baseline. Patients with combined end-point were more frequently characterized by a multivessel CAD (81.4 vs. $43.1 \%$; $\mathrm{p}<0.001)$ and a history of MI (62.8 vs. $39.7 \%$; $\mathrm{p}<$ 0.01 ). Combined end-point tended to occur more frequently in men than in women. There were no significant differences in age, office SBP and DBP levels, mean 24hour DBP, diabetes mellitus and smoking status, number 
Table 4. Baseline clinical characteristics of patients according to the occurrence of end-point

\begin{tabular}{|c|c|c|c|}
\hline & Patients without end-point & Patients with end-point & $\mathrm{p}$ \\
\hline Number & 217 & 43 & - \\
\hline Age, years & $56.1 \pm 9.6$ & $58.6 \pm 10.1$ & ns \\
\hline Female gender, $\%$ & 33 & 19 & 0.059 \\
\hline BMI & $28.8 \pm 3.9$ & $28.8 \pm 3.1$ & ns \\
\hline BP office, $\mathrm{mm} \mathrm{Hg}$ & $137 \pm 23 / 85 \pm 14$ & $133 \pm 17 / 81 \pm 12$ & $\mathrm{~ns} / \mathrm{ns}$ \\
\hline BP 24-hour, mm Hg & $116 \pm 13 / 71 \pm 8$ & $124 \pm 12 / 74 \pm 8$ & $<0.001 / 0.1$ \\
\hline $\mathrm{HR}$, beats/min & $68.5 \pm 7.2$ & $71.2 \pm 7.9$ & $<0.05$ \\
\hline PP office, $\mathrm{mm} \mathrm{Hg}$ & $48 \pm 13$ & $48 \pm 14$ & ns \\
\hline PP 24-hour, mm Hg & $45 \pm 10$ & $51 \pm 10$ & $<0.01$ \\
\hline History of MI, \% & 40.1 & 62.8 & $<0.01$ \\
\hline Diabetes mellitus, \% & 13.9 & 25.6 & 0.055 \\
\hline Hyperlipidemia, \% & 71.1 & 83.7 & 0.088 \\
\hline Multivessel disease, $\%$ & 42.9 & 81.4 & $<0.001$ \\
\hline Carotid arteries atherosclerosis, \% & 74 & 85 & ns \\
\hline Renal arteries atherosclerosis, \% & 16.1 & 14.0 & ns \\
\hline Femoral arteries atherosclerosis, \% & 72.9 & 85.0 & 0.11 \\
\hline Former or current smokers, $\%$ & 23.1 & 20.9 & ns \\
\hline EF echocardiography, \% & $62.4 \pm 9.9$ & $60.2 \pm 11.1$ & ns \\
\hline $\mathrm{IMT}, \mathrm{mm}$ & $1.14 \pm 0.35$ & $1.25 \pm 0.43$ & 0.091 \\
\hline LVMI, $\mathrm{g} / \mathrm{m}^{2}$ & $119.3 \pm 29.8$ & $126.9 \pm 34.2$ & ns \\
\hline Nitrates, $\%$ & 61.3 & 69.8 & ns \\
\hline Diuretics, $\%$ & 16.6 & 20.9 & ns \\
\hline$\beta$-Blockers, \% & 82.9 & 83.9 & ns \\
\hline ACEI or ARB, $\%$ & 77.9 & 69.7 & ns \\
\hline $\mathrm{CCB}, \%$ & 51.6 & 62.8 & ns \\
\hline Statins, \% & 52.5 & 60.5 & ns \\
\hline Number of antihypertensive drugs ${ }^{\mathrm{a}}$ & 2 & 2 & ns \\
\hline CCS class $^{\mathrm{a}}$ & 2 & 2.5 & $<0.05$ \\
\hline Cystatin C, nmol/1 & $86.1 \pm 24.0$ & $93.6 \pm 24.0$ & 0.055 \\
\hline Creatinine, $\mu \mathrm{mol} / \mathrm{l}$ & $108.1 \pm 27.8$ & $111.8 \pm 20.1$ & ns \\
\hline Creatinine clearance, $\mathrm{ml} / \mathrm{min}$ & $81.4 \pm 24.2$ & $78.6 \pm 21.2$ & ns \\
\hline $\mathrm{GFR}, \mathrm{ml} / \mathrm{min} / 1.73 \mathrm{~m}^{2}$ & $64.6 \pm 13.6$ & $63.2 \pm 12.2$ & ns \\
\hline Uric acid, $\mathrm{mmol} / \mathrm{l}$ & $5.0 \pm 1.4$ & $5.1 \pm 1.1$ & ns \\
\hline Leukocytes, $10^{3} / \mu \mathrm{l}$ & $7.0 \pm 2.0$ & $7.2 \pm 1.8$ & ns \\
\hline Hemoglobin, g/dl & $14.2 \pm 1.3$ & $15.6 \pm 6.5$ & ns \\
\hline Platelets, $10^{3} / \mu \mathrm{l}$ & $216 \pm 62$ & $217 \pm 55$ & ns \\
\hline Fibrinogen, $\mu \mathrm{mol} / \mathrm{l}$ & $10.2 \pm 3.0$ & $10.1 \pm 2.2$ & ns \\
\hline Serum Na, mmol/l & $141.3 \pm 3.2$ & $141.1 \pm 3.0$ & ns \\
\hline Serum K, mmol/l & $4.5 \pm 0.4$ & $4.4 \pm 0.4$ & ns \\
\hline hsCRP, mg/l & $5.4 \pm 3.8$ & $6.0 \pm 4.0$ & ns \\
\hline Serum cholesterol, mmol/l & $5.1 \pm 1.0$ & $4.9 \pm 0.9$ & ns \\
\hline Serum triglyceride, $\mathrm{mmol} / \mathrm{l}$ & $1.9 \pm 1.0$ & $1.8 \pm 0.8$ & ns \\
\hline $\mathrm{HDL}, \mathrm{mmol} / \mathrm{l}$ & $1.2 \pm 0.3$ & $1.2 \pm 0.3$ & ns \\
\hline $\mathrm{LDL}, \mathrm{mmol} / \mathrm{l}$ & $3.0 \pm 0.9$ & $3.0 \pm 0.9$ & ns \\
\hline Fasting blood glucose, $\mathrm{mmol} / \mathrm{l}$ & $5.7 \pm 1.3$ & $6.3 \pm 2.1$ & 0.114 \\
\hline Homocysteine, $\mu \mathrm{mol} / \mathrm{l}$ & $11.4 \pm 4.4$ & $11.1 \pm 3.4$ & ns \\
\hline
\end{tabular}

$\mathrm{BMI}=$ Body mass index; $\mathrm{BP}=$ blood pressure $\mathrm{HR}=$ heart rate; $\mathrm{PP}=$ pulse pressure $\mathrm{MI}=$ myocardial infarction; $\mathrm{EF}=$ ejection fraction; IMT = intima media thickness; LVMI = left ventricle mass index; ACEI = angiotensin-converting enzyme inhibitor; $\mathrm{ARB}=$ angiotensin II receptor blocker; $\mathrm{CCB}=$ calcium channel blocker; CCS = Canadian Cardiovascular Society; GFR = glomerular filtration rate; hsCRP = high-sensitivity C-reactive protein; $\mathrm{HDL}=$ high-density lipoprotein; $\mathrm{LDL}=$ low-density lipoprotein. ${ }^{\text {a }}$ Data are shown as median. 


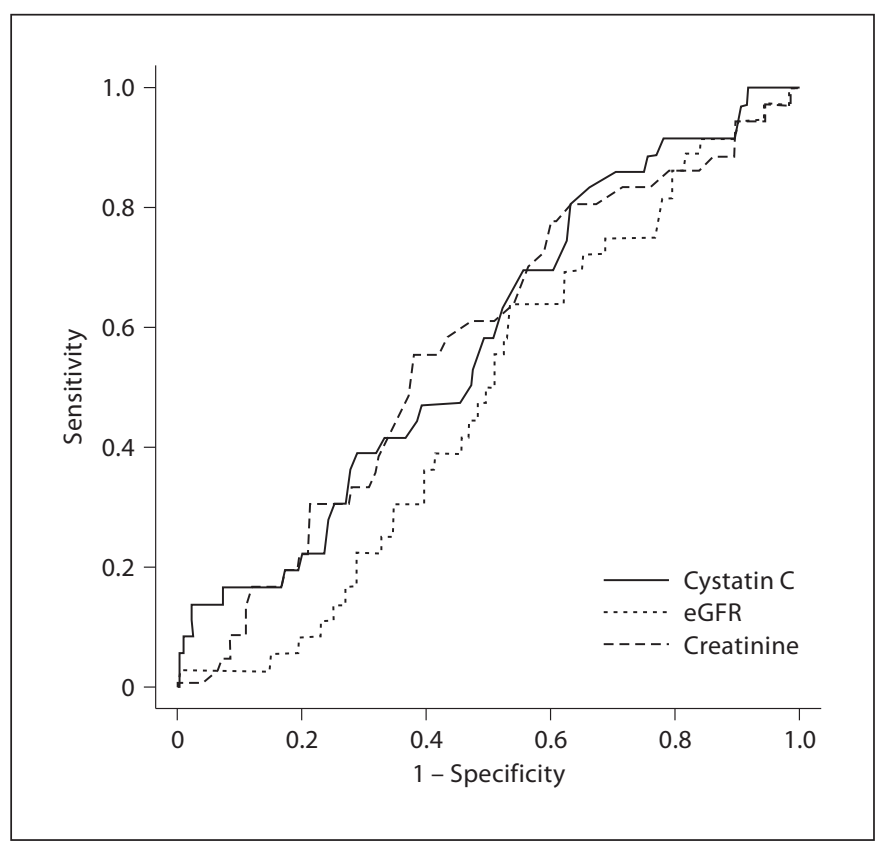

Fig. 1. ROC curve with regard to composite end-point at 40 months for cystatin C, creatinine concentrations and eGFR with area under curve of 58 (95\% CI $0.48-0.67), 0.57$ (95\% CI $0.47-$ 0.67 ) and 0.48 (95\% CI 0.39-0.57), respectively.

of antihypertensive drugs as well in serum creatinine, hsCRP, fibrinogen concentrations and ejection fraction between patients with and without combined end-point.

In the comparison of the markers of renal function in ROC analyses, serum cystatin $C$ concentration was characterized by a moderately better ability than serum creatinine and eGFR to discriminate patients with and without an end-point at 40 months (fig. 1). Area under the curve was 0.58 (95\% CI $0.48-0.67$ ) for serum cystatin C, 0.57 (95\% CI $0.47-0.67$ ) for serum creatinine and 0.48 (95\% CI 0.39-0.57) for eGFR. However, it should be noted that differences in the prediction value between each parameter were not significant.

The risk of combined end-point increased with increasing levels of serum cystatin C (fig. 2). Combined end-point occurred twice as more frequently in the 4th quartile of serum cystatin $\mathrm{C}$ as compared with the 1st quartile of serum cystatin C (10.8 vs. $20.3 \%)$. However, these differences were not significant $(\mathrm{p}=0.11)$.

In a univariate Cox regression analysis, significant predictors of the combined end-point were 24-hour SBP, $\mathrm{HR}$, history of MI, multivessel disease and serum cystatin C concentration (table 5). In a multivariate Cox model that included all variables with a value of $p<0.05$ in an

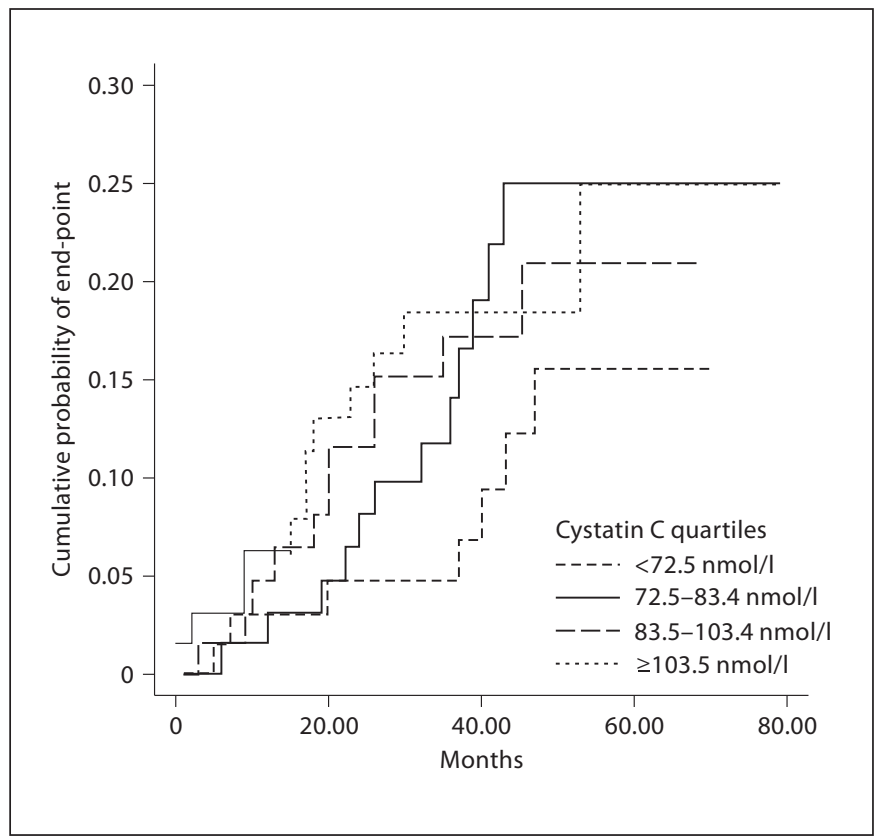

Fig. 2. Cumulative probability of end-point in patients with cystatin $\mathrm{C}<72.5 \mathrm{nmol} / \mathrm{l}(\mathrm{n}=65), 72.5-83.4 \mathrm{nmol} / \mathrm{l}(\mathrm{n}=64), 83.5-$ $103.4 \mathrm{nmol} / \mathrm{l}(\mathrm{n}=67)$ and $\geq 103.5 \mathrm{nmol} / \mathrm{l}(\mathrm{n}=64)$. Group $<72.5$ $\mathrm{nmol} / \mathrm{l}$ vs. group $\geq 103.5 \mathrm{nmol} / \mathrm{l}$ : $\log$-rank $\mathrm{p}=0.1$.

univariate analysis, the multivessel disease and 24-hour SBP level (for $10 \mathrm{~mm} \mathrm{Hg}$ increase) but not serum cystatin C independently predicted occurrence of combined endpoint (table 5).

\section{Discussion}

The present study showed that in a group of hypertensive patients with CAD, serum cystatin C level was independently associated with the extent of CAD and traditional vascular risk factors including homocysteine, hsCRP and fibrinogen plasma levels. We also found that subjects in the high serum cystatin $\mathrm{C}$ quartile were older and were characterized by higher serum hsCRP and fibrinogen plasma levels as compared with those with the lowest quartile. Additionally, subjects in the high serum cystatin $\mathrm{C}$ quartile had more often multivessel CAD and more pronounced increase in IMT.

The present results extend the findings from previous studies in several ways. We have demonstrated that in hypertensive patients with CAD and normal to moderate renal impairment, serum cystatin C level was associated with the extent of coronary atherosclerosis, as expressed 
Table 5. Combined end-point: univariate and multivariate analysis

\begin{tabular}{|c|c|c|c|c|c|c|c|c|}
\hline \multirow[t]{2}{*}{ Variable } & \multicolumn{4}{|c|}{ Univariate } & \multicolumn{4}{|c|}{ Multivariate } \\
\hline & $\operatorname{Exp}(B)$ & $95 \% \mathrm{C}$ & & $\mathrm{p}$ & $\operatorname{Exp}(B)$ & $95 \% \mathrm{C}$ & & $\mathrm{p}$ \\
\hline Gender & - & - & - & ns & - & - & - & - \\
\hline 24-hour SBP (for $10 \mathrm{~mm} \mathrm{Hg}$ increase) & 1.442 & 1.163 & 1.787 & $<0.01$ & 1.369 & 1.106 & 1.696 & 0.01 \\
\hline HR & 1.043 & 1.003 & 1.084 & $<0.05$ & - & - & - & - \\
\hline History of MI & 2.165 & 1.165 & 4.021 & $<0.05$ & - & - & - & - \\
\hline Multivessel disease & 5.004 & 2.321 & 10.790 & $<0.001$ & 6.099 & 2.374 & 15.669 & $<0.001$ \\
\hline Cystatin C concentration (for $7.5 \mathrm{nmol} / 1$ increase) & 1.096 & 1.001 & 1.200 & $<0.05$ & - & - & - & - \\
\hline
\end{tabular}

$\mathrm{CI}=$ Confidence interval; $\mathrm{SBP}=$ systolic blood pressure; $\mathrm{HR}=$ heart rate; $\mathrm{MI}=$ myocardial infarction.

by multivessel disease. Our study appears to confirm other reports and only one study failed to demonstrate an association between serum cystatin $\mathrm{C}$ serum levels and the number of stenosed coronary vessels in young survivors of MI [12].

It has been shown by Niccoli et al. [13] that in patients with CAD and with normal eGFR, serum cystatin C levels independently predicted the extent of coronary atherosclerotic burden (according to Sullivan's score and lesion morphology) and a predominant stable plaque phenotype. However, it should be noted that in the present report the relation between serum cystatin $\mathrm{C}$ and coronary atherosclerosis was assessed in CAD patients with a mean eGFR of $64.3 \mathrm{ml} / \mathrm{min} / 1.73 \mathrm{~m}^{2}$ and without significant renal artery stenosis in order to avoid the well-known effect of severe renal impairment on coronary atherosclerosis.

Muntner et al. [10] also reported a graded association between higher serum cystatin $C$ concentration and increased prevalence of cardiovascular disease in patients with normal renal function. Thus, the association of cystatin C levels with the extent of CAD found in our study might be mediated by mildly impaired renal function. Multiple mechanisms have been postulated potentially explaining the association between renal dysfunction and CAD including endothelial dysfunction, enhanced oxidative stress and reduction of anti-inflammatory cytokines. Our data are also in agreement with the results of Wang et al. [14] who showed that in patients with CAD and mild renal impairment, plasma cystatin $C$ was most predictive of both occurrence and severity of CAD. Our data are in line with previous reports indicating that in a large group of patients with and without CAD and even mild renal impairment, elevated serum cystatin $C$ levels were significantly associated with traditional vascular risk factors including homocysteine and hsCRP. It has also been reported that cystatin $\mathrm{C}$ was also associated with newer risk factors, namely asymmetric dimethylarginine and symmetric dimethylarginine [14].

We demonstrated the relationship between serum cystatin $\mathrm{C}$ and homocysteine plasma concentration. It has also been found that subjects in the higher serum cystatin C quartiles were characterized by a higher level of homocysteine. Data regarding the association between reduced kidney function estimated by cystatin $\mathrm{C}$ and homocysteine plasma level in hypertensive patients with CAD are limited. In only one study by Wang et al. [14] the elevated serum cystatin C level was found to be significantly associated with serum homocysteine level.

It is widely accepted that homocysteine can be considered as an independent risk factor for cardiovascular disease [15]. Many studies have shown that increased plasma homocysteine levels in patients presenting with acute coronary syndromes are independent predictors of recurrent cardiovascular events [16-18]. Therefore, the accumulated data so far provide strong evidence supporting a putative role of homocysteine in atherosclerosis. However, it is still unclear whether homocysteinemia is a modifiable risk factor in atherosclerosis. Recent data indicate that high-dose B vitamin supplementation significantly reduces progression of early-stage subclinical atherosclerosis (carotid IMT) in healthy individuals at low risk for cardiovascular disease $[19,20]$. It has also been shown that in patients with moderate-severe chronic HF mildly elevated levels of plasma homocysteine are related to poor survival independently of other established prognostic factors [21].

The recent cross-sectional PREVEND study showed that serum cystatin $C$ concentrations were significantly associated with $\mathrm{C}$-reactive protein, smoking and body 
mass index even after adjustment for creatinine clearance. It has been suggested that the univariate association between higher serum cystatin Clevels and higher hsCRP levels may be partially explained by the fact that obesity and smoking are both associated with increased hsCRP levels. The results indicate that serum cystatin $C$ levels do appear to be influenced by multiple factors other than renal function and may also be one of the biomarkers of inflammation [22].

Singh et al. [23] also reported a significant association between serum cystatin C concentration, serum hsCRP and fibrinogen serum levels in subjects with CAD enrolled in the Heart and Soul Study. It has also been found that quartiles of serum cystatin $\mathrm{C}$ were strongly associated with serum hsCRP and fibrinogen concentration suggesting linear associations with these two inflammatory markers. This is supported by Muntner et al. [10] who also reported that increased hsCRP was higher at higher serum cystatin $\mathrm{C}$ quartiles.

In only one report based on a small number of patients with CAD no correlation was found between serum cystatin C and serum hsCRP levels [13]. More recently it has been shown that higher serum cystatin $\mathrm{C}$ concentrations are strongly associated with left ventricular hypertrophy and diastolic dysfunction in outpatients with CAD but without HF [24]. However, whether serum cystatin C is associated with other structural and functional abnormalities in CAD patients with normal renal function or mild renal dysfunction estimated by eGFR is not clearly established. Carotid IMT is an intermediate phenotype for early atherosclerosis and a number of studies have examined the relationship between IMT and future events, most frequently the incidence of cardiac and/or cerebrovascular events $[25,26]$. However, there are limited data providing information about associations of serum cystatin C plasma level and IMT in patients with CAD. Recently, it has been reported that there is no relationship between cystatin $\mathrm{C}$ and IMT in the group of young to middle-aged subjects of African descent [27]. Our study indicates that hypertensive patients with CAD in the high serum cystatin $\mathrm{C}$ quartile had a more pronounced increase in IMT. We also found an univariate association between serum cystatin C plasma level and IMT. This may suggest that in our group of patients, cystatin $\mathrm{C}$ may be related to IMT, a surrogate marker of early atherosclerosis. Our results appear to confirm the recent results of Skalska et al. [28] who showed that the serum cystatin C level was associated with carotid intima-media thickening in middle-aged and elderly treated hypertensive patients without CAD.
In our study, all 260 patients were followed up at mean 40 months and we have shown that subjects with combined end-point were characterized by a significantly higher serum cystatin $\mathrm{C}$ concentration at baseline. $\mathrm{Pa}-$ tients with combined end-point had higher mean 24hour SBP levels, 24-hour PP and HR at baseline. Patients with combined end-point had more frequently multivessel CAD and a history of MI. Combined end-point tended to occur more frequently in men than in women. The risk of combined end-point increased with increasing levels of serum cystatin Clevels. Combined end-point occurred twice as frequently in the 4 th cystatin $\mathrm{C}$ quartile as compared with the 1st cystatin $\mathrm{C}$ quartile, nonetheless the difference was not significant.

Recent studies have demonstrated that the risk of death during the follow-up period increased with increasing levels of cystatin C. In the group with non-ST elevation MI, patients in the second, third and fourth quartiles had a relative risk of subsequent death of 1.8, 3.2 and 11.7 compared with the lowest quartile [7].

Data from the Heart and Soul Study showed that compared with participants in the lowest serum cystatin C quartile, those in the highest quartile were at increased risk of all-cause mortality, cardiovascular events and incidence of HF [6]. Koenig et al. [29] also found that patients in the top quintile of the serum cystatin $\mathrm{C}$ distribution at baseline had a significantly increased risk of secondary cardiovascular events even after adjustment for classic risk factors or severity of CAD.

In the present study, significant predictors of the combined end-point in a univariate analysis were 24-hour SBP, $\mathrm{HR}$, history of MI, multivessel disease and serum cystatin C concentration, however, in a multivariate model only the multivessel disease and 24-hour SBP level (for $10 \mathrm{~mm} \mathrm{Hg}$ increase) but not serum cystatin $\mathrm{C}$ independently predicted occurrence of combined end-point. It should be noted, however, that several studies reported that the serum cystatin $\mathrm{C}$ level was associated with increased all-cause and cardiovascular mortality during follow-up [6-11].

Jernberg et al. [7] determined that elevated serum cystatin $\mathrm{C}$ level was associated with mortality among subjects hospitalized with acute MI, and Koenig et al. [29] demonstrated that an increased cystatin $\mathrm{C}$ level predicted secondary cardiovascular events among a cohort participating in an in-hospital rehabilitation program shortly after acute MI or coronary revascularization.

Data from the Heart and Soul Study also added to the existing literature by demonstrating that serum cystatin C concentrations predict not only cardiovascular events but also mortality and incidence of HF among ambulatory pa- 
tients with CAD [6]. We have also found that in comparison with the other markers of renal function in ROC analyses, serum cystatin $C$ concentration was characterized by a moderately better ability than serum creatinine concentration or eGFR to discriminate patients with and without end-point at 40 months. However, it should be noted that the prediction value of each parameter was not significant.

Several reports have indicated that in the elderly community-based cohorts, serum cystatin $\mathrm{C}$ concentration seems to be a better predictor of all-cause mortality, cardiovascular events and incidence of HF than either serum creatinine or creatinine-based estimating equations [29, 30]. A recent study showed that in patients with CAD, only serum cystatin $\mathrm{C}$, but not serum creatinine or creatinine clearance, was associated with secondary cardiovascular events during a 3-year follow-up [7]. However, Knight et al. [22] reported that serum cystatin C-based estimates of renal function do not appear to be superior to serum creatinine-based estimates of renal function.

Our study has several limitations. First, our results apply predominantly to patients having $\mathrm{CAD}$, who met one of the predefined selection criteria - hypertension stage $1-3$. It is difficult to ascertain to what extent our results may be generalized to the whole population of patients with CAD, and our patients represent a random sample of hypertensive patients with CAD. It should also be borne in mind that the associations we have observed between serum cystatin $\mathrm{C}$ concentration and coronary disease as well as other risk factors (including homocysteine, hsCRP and fibrinogen) may simply reflect generalized atherosclerosis and/or mildly impaired renal function. Also in contrast with the prior epidemiologic studies in a commu- nity-based cohort, our sample size is relatively small. Moreover, only a medium follow-up period (40 months) was performed. It should also be noted that monitored values of BP could have been influenced by the suitability of antihypertensive treatment during the in-hospital stay.

The present study needs to be interpreted in the context of its limitations. However, our results extend the findings from previous studies in several ways. In conclusion, the present study showed that in a group of hypertensive patients with CAD, serum cystatin C level was independently associated with the extent of CAD and traditional vascular risk factors including serum hsCRP and fibrinogen levels. We demonstrated the association between reduced kidney function estimated by cystatin C and homocysteine plasma level in hypertensive patients with CAD. We also found that subjects in the high cystatin $\mathrm{C}$ quartile had more often multivessel CAD and more pronounced increase in IMT. We found that the risk of combined end-point was greater with increased levels of serum cystatin $\mathrm{C}$ concentration. Combined end-point occurred more frequently in the highest serum cystatin $\mathrm{C}$ quartile as compared with the lowest quartile. Nonetheless, the difference was not significant. In contrast to other reports based on the large number of participants, serum cystatin $C$ concentration in our study was not a predictor of the occurrence of combined end-point.

\section{Acknowledgement}

The study was supported by a grant from the Polish Committee for Scientific Investigation No. 4P05B 14418.

\section{References}

1 Shlipak MG, Sarnak MJ, Katz R, Fried LF, Seliger SL, Newman AB, Siscovick DS, Stehman-Breen C: Cystatin C and the risk of death and cardiovascular events among elderly persons. N Engl J Med 2005;352:20492060.

$\checkmark 2$ Stevens LA, Coresh J, Greene T, Levey AS: Assessing kidney function - measured and estimated glomerular filtration rate. $\mathrm{N}$ Engl J Med 2006;354:2473-2483.

3 Madero M, Sarnak MJ, Stevens LA: Serum cystatin $\mathrm{C}$ as a marker of glomerular filtration rate. Curr Opin Nephrol Hypertens 2006;15:610-616.

4 Schiffrin EL, Lipman ML, Mann JF: Chronic kidney disease: effects on the cardiovascular system. Circulation 2007;116:85-97.
5 Dzielinska Z, Januszewicz A, Demkow M, Makowiecka-Ciesla M, Prejbisz A, Naruszewicz M, Nowicka G, Kadziela J, Zielinski T, Florczak E, Janas J, Januszewicz M, Ruzyllo $\mathrm{W}$ : Cardiovascular risk factors in hypertensive patients with coronary artery disease and coexisting renal artery stenosis. J Hypertens 2007;25:663-670.

6 Ix JH, Shlipak MG, Chertow GM, Whooley MA: Association of cystatin C with mortality, cardiovascular events, and incident heart failure among persons with coronary heart disease: data from the Heart and Soul Study. Circulation 2007;115:173-179.

7 Jernberg T, Lindahl B, James S, Larsson A, Hansson LO, Wallentin L: Cystatin C: a novel predictor of outcome in suspected or confirmed non-ST elevation acute coronary syndrome. Circulation 2004;110:2342-2348.
8 Maahs DM, Ogden LG, Kretowski A, SnellBergeon JK, Kinney GL, Berl T, Rewers M: Serum cystatin $\mathrm{C}$ predicts progression of subclinical coronary atherosclerosis in individuals with type 1 diabetes. Diabetes 2007; 56:2774-2779.

>9 Menon V, Shlipak MG, Wang X, Coresh J, Greene T, Stevens L, Kusek JW, Beck GJ, Collins AJ, Levey AS, Sarnak MJ: Cystatin C as a risk factor for outcomes in chronic kidney disease. Ann Intern Med 2007;147:19-27.

$>10$ Muntner P, Mann D, Winston J, Bansilal S, Farkouh ME: Serum cystatin $C$ and increased coronary heart disease prevalence in US adults without chronic kidney disease. Am J Cardiol 2008;102:54-57. 
11 Shlipak MG, Wassel Fyr CL, Chertow GM, Harris TB, Kritchevsky SB, Tylavsky FA, Satterfield S, Cummings SR, Newman AB, Fried LF: Cystatin $\mathrm{C}$ and mortality risk in the elderly: the health, aging, and body composition study. J Am Soc Nephrol 2006;17:254261.

12 Eriksson P, Deguchi H, Samnegard A, Lundman P, Boquist S, Tornvall P, Ericsson CG, Bergstrand L, Hansson LO, Ye S, Hamsten A: Human evidence that the cystatin $\mathrm{C}$ gene is implicated in focal progression of coronary artery disease. Arterioscler Thromb Vasc Biol 2004;24:551-557.

13 Niccoli G, Conte M, Della Bona R, Altamura L, Siviglia M, Dato I, Ferrante G, Leone AM, Porto I, Burzotta F, Brugaletta S, Biasucci LM, Crea F: Cystatin C is associated with an increased coronary atherosclerotic burden and a stable plaque phenotype in patients with ischemic heart disease and normal glomerular filtration rate. Atherosclerosis 2008; 198:373-380.

14 Wang J, Sim AS, Wang XL, Salonikas C, Moriatis $M$, Naidoo D, Wilcken DE: Relations between markers of renal function, coronary risk factors and the occurrence and severity of coronary artery disease. Atherosclerosis 2008; 197:853-859.

15 Antoniades C, Antonopoulos AS, Tousoulis D, Marinou K, Stefanadis C: Homocysteine and coronary atherosclerosis: from folate fortification to the recent clinical trials. Eur Heart J 2009;30:6-15.

16 Akhtar N: Is homocysteine a risk factor for atherothrombotic cardiovascular disease? J Am Coll Cardiol 2007;49:1370-1371.
7 Bonaa KH, Njolstad I, Ueland PM, Schirmer $H$, Tverdal A, Steigen T, Wang H, Nordrehaug JE, Arnesen E, Rasmussen K: Homocysteine lowering and cardiovascular events after acute myocardial infarction. N Engl J Med 2006;354:1578-1588.

18 Wald DS, Law M, Morris JK: Homocysteine and cardiovascular disease: evidence on causality from a meta-analysis. BMJ 2002;325: 1202.

19 Hodis HN, Mack WJ, Dustin L, Mahrer PR, Azen SP, Detrano R, Selhub J, Alaupovic P, Liu CR, Liu CH, Hwang J, Wilcox AG, Selzer RH: High-dose B vitamin supplementation and progression of subclinical atherosclerosis: a randomized controlled trial. Stroke 2009;40:730-736.

20 Jax T, Lauer T: The art of primary prevention and risk assessment: homocysteine revisited. Stroke 2009;40:670-671.

21 Naruszewicz M, Jankowska EA, Zymlinski R, Bukowska H, Millo B, Banasiak W, Ponikowski P: Hyperhomocysteinemia in patients with symptomatic chronic heart failure: prevalence and prognostic importance - pilot study. Atherosclerosis 2007;194: 408-414.

-22 Knight EL, Verhave JC, Spiegelman D, Hillege HL, de Zeeuw D, Curhan GC, de Jong PE: Factors influencing serum cystatin $C$ levels other than renal function and the impact on renal function measurement. Kidney Int 2004;65:1416-1421.

-23 Singh D, Whooley MA, Ix JH, Ali S, Shlipak MG: Association of cystatin C and estimated GFR with inflammatory biomarkers: the Heart and Soul Study. Nephrol Dial Transplant 2007;22:1087-1092.

-24 Ix JH, Shlipak MG, Chertow GM, Ali S, Schiller NB, Whooley MA: Cystatin C, left ventricular hypertrophy, and diastolic dysfunction: data from the Heart and Soul Study. J Card Fail 2006;12:601-607.
25 Lorenz MW, Markus HS, Bots ML, Rosvall M, Sitzer M: Prediction of clinical cardiovascular events with carotid intima-media thickness: a systematic review and metaanalysis. Circulation 2007;115:459-467.

-26 O'Leary DH, Polak JF, Kronmal RA, Manolio TA, Burke GL, Wolfson SK Jr: Carotidartery intima and media thickness as a risk factor for myocardial infarction and stroke in older adults. Cardiovascular Health Study Collaborative Research Group. N Engl J Med 1999;340:14-22.

$\checkmark 27$ Rodondi N, Yerly P, Gabriel A, Riesen WF, Burnier M, Paccaud F, Bovet P: Microalbuminuria, but not cystatin $\mathrm{C}$, is associated with carotid atherosclerosis in middle-aged adults. Nephrol Dial Transplant 2007;22: 1107-1114.

-28 Skalska A, Klimek E, Wizner B, Gasowski J, Grodzicki T: Kidney function and thickness of carotid intima-media complex in patients with treated arterial hypertension. Blood Press 2007; 16:367-374.

29 Koenig W, Twardella D, Brenner H, Rothenbacher D: Plasma concentrations of cystatin C in patients with coronary heart disease and risk for secondary cardiovascular events: more than simply a marker of glomerular filtration rate. Clin Chem 2005;51:321-327.

-30 Shlipak MG, Katz R, Sarnak MJ, Fried LF, Newman AB, Stehman-Breen C, Seliger SL, Kestenbaum B, Psaty B, Tracy RP, Siscovick DS: Cystatin C and prognosis for cardiovascular and kidney outcomes in elderly persons without chronic kidney disease. Ann Intern Med 2006;145:237-246. 